\title{
The Causes of Pragmatic Failure from the Perspective of Bilingualism and its Implications for Foreign Language Teaching
}

\author{
Shaoxia Liu ${ }^{1}$, Mun-Koo Kang ${ }^{2}$ \\ ${ }^{1}$ Graduate Student, English Education, Kongju National University, Korea, 327724350@qq.com \\ ${ }^{2}$ Professor, English Education, Kongju National University, Korea, kangmunkoo@ hanmail.net
}

Corresponding author: Mun-Koo Kang

\begin{abstract}
Pragmatics theory began to be studied and developed in China in the 1980s and 1990s. Among the various branches and concepts of pragmatics, pragmatic failure is an important aspect that cannot be ignored. In recent decades, there has been a variety of developments in the field of pragmatics. Many studies use the method of contrastive analysis to summarize the types of failures in communication between English and Chinese users. In addition to linguistic pragmatic failures, there are also social pragmatic failures and even non-verbal pragmatic failures. Most of these types of failures focus on the fact that Chinese students are the initiators of pragmatic failures. However, with the development of internationalization and the emergence of "Chinese fever", more and more Westerners will also produce pragmatic failures in the process of using Chinese, which will lead to the failure of communication as well. The first part of this paper analyzes the research background by using the method of literature analysis, pointing out the direction of pragmatic research in China, such as various discourse acts, adaptation theory, pragmatic failure in translation aspects. The second part uses the contrastive study method based on the phenomenon to compare the main causes of pragmatic failure. The causes are the differences in culture, thinking pattern and lacking pragmatic knowledge, teachers or other educators should pay attention to the emphasis and input of pragmatic awareness and pragmatic knowledge. In order to avoid pragmatic failure, the third part proves some strategies.

The experimental method proves that pragmatic teaching is helpful to the improvement of pragmatic competence. English is a common language in the world, so the importance of English pragmatics has been well known by learners; however, with the increase in non-native learners of Chinese, in the bilingual environment, language learners should also pay more and more attention to the understanding of Chinese culture.
\end{abstract}

Keywords: Pragmatic Failure, Cause, Culture, Patterns of Thoughts, Pragmatic Knowledge, Teachers, Real Context

\section{Introduction}

The concept of pragmatic failure as a separate concept began with the publication of Cross-Cultural Pragmatic Failure by British linguist Jenny Thomas in 1983. In her book, communication failure is called "pragmatic failure"[1]. She classifies pragmatic failure into two categories. One is the pragmalinguistic failure; that is, pragmatic failure of language itself. The reason for this kind of pragmatic failure is that non-native language users apply the language and structure of the mother

Received: August 19, 2020; 1st Review Result: October 03, 2020; 2nd Review Result: November 19, 2020 Accepted: December 28, 2020 
language to the language customs and language structure of the target language, which can lead to cognitive bias between different languages. The second category is sociopragmatic failure, which means that in the social context, speakers with different cultural backgrounds produce physiological misunderstandings due to the cognitive bias of the implied meaning of the discourse, which makes the discourse ambiguous due to differences in cognitive structure.

Leech has discussed the social conditions of language use and social pragmatic failure. He believes that "the pragmatic differences of greetings and compliments between English and Chinese in daily verbal communication may lead to social pragmatic failure."

In recent years, western studies have paid more attention to the ontological analysis of crosscultural pragmatic failure. Western linguists have made a specific comparison of the definition, types, causes, consequences of cross-cultural pragmatic failure, and elaborated on its internal relations from the perspective of linguistics. Relevance : Communication and Cognition published by Sperber and Wilson (1986)[2], put forward the relevance theory of cognitive pragmatics, which is quite different from Grice's cooperative principle. Relevance theory not only provides a new theoretical framework for the study of pragmatic discourse, but also broadens the way of thinking in the fields of psychology and philosophy.

There are many new perspectives in the study of pragmatic failure in China, such as some speech acts in greeting, refusal, criticism, invitation, expressions of gratitude, apology, request and so on. There are also studies on pragmatic failure in translation, such as the translation of place names, school names, road signs, etc.

Some scholars have done some research on pragmatic failure from the perspective of adaptation theory, cognitive perspective, pragmatic vagueness theory and empathy theory.

For example, Hong Gang(1991)[3] believes that "The pragmatic rules and cultural factors of students' mother tongue are acquired since childhood, the pragmatic rules and cultural factors are their mode of thinking and code of conduct." Therefore, the habits of one's mother tongue expression interfere with the use of foreign language and affect cognitive expression.

XiongYanbing(2008)[4] mainly discusses the grammatical errors and pragmatic failures in second language acquisition and analyzes the causes.

LvTiejin(2016)[5] analyzes the pragmatic failure in the process of cross-cultural communication through individual examples, and puts forward the coping strategies for pragmatic failure. After discussing the causes and categories of pragmatic failure.

Hao Ying(2017)[6]puts forward the strategies for avoiding or reducing pragmatic failure, which can help foreign language users understand which language is consistent with the relevant context and culture in verbal communication, so that they can achieve successful cross-cultural communication by making appropriate choices. From the perspective of adaptation theory.

Chen Yating(2008)[7] explains the root causes of interlingual pragmatic failure and intralingual pragmatic failure. She believes that pragmatic failure is caused by the fact that people ignore the dynamic adaptation between language and communicative context (such as individuals, physical factors, social factors, psychological factors, etc.). According to the relationship between pragmatic competence and pragmatic transfer.

Dai Yuanfang (2019)[8] proposes three different stages of pragmatic teaching strategies for Chinese EFL learners at three levels: low, medium and high. In his Book Pragmatics: phenomena and analysis, Ran Yongping believes that English teachers should not only pay attention to language ontology teaching, but also broaden their horizons and interpenetrate the knowledge of pragmatics and other branches of linguistics into their daily teaching.

Domestic Chinese research focuses on cross-cultural pragmatic failure from multiple inter disciplinary angles. Scholars apply cross-cultural pragmatic failures to language teaching, cultural teaching, etc., hoping to find the characteristics and rules of pragmatic failures in Chinese in the new 
environment (Zhang,2019)[9].

According to the statistics of China's Ministry of Education, in 2020, the number of higher education institutions is 8,341 and the number of the students is 97,097,886. All colleges and universities have opened English courses. Similarly, according to the statistics of China's Confucius Institute worldwide, at least 100 million people were learning Chinese in 2018.

In such a bilingual environment, Non-native learners of Chinese and Chinese learners of English will inevitably produce pragmatic failure in the process of communication. In view of the types of these failures, predecessors have done a lot of research, and the author has also published on the types of pragmatic failures in a paper in 2019[10]. Based on those pragmatic failure phenomena in former researches and my Chinese teaching experience. This paper classifies the causes of pragmatic failure and proves some strategies on the teaching process and uses an experiment to verify the validity of the pragmatic teaching to avoid the pragmatic failure in the future.

\section{The Causes of Pragmatic Failure}

According to the previous pragmatic theories, this chapter uses the method of comparison between English and Chinese and literature research method to summarize the causes of pragmatic failure from three aspects: cultural aspects, patterns of thoughts, and lack of pragmatic theories.

\subsection{Differences in Cultural Psychology}

Due to differences in geographical location, natural environment, historical changes, religious beliefs, and economic development levels, all national groups have formed their own national and social attributes of culture. Language is the carrier of culture. Language conveys a nation's traditions, thoughts, customs, emotions and other factors. The lack of understanding of other people's language and culture, thinking mode, values and behavior norms will inevitably lead to various pragmatic failures in cross-cultural communication (Guan Zhenbin, 2007)[11].

Therefore, we should be aware of cultural differences and seek to understand each other's culture in daily cross-cultural communication, so as to ensure the smooth progress of communication.

In western culture, due to the long-term wars and colonialism between countries and nations in history, as well as the factors of trade and marriage, people with different cultural backgrounds in different countries and regions are forced to gather and finally integrate. In this multicultural historical background, it is difficult to achieve collective unity, so individualism is highly valued.

People emphasize people's freedom, rights and independence in their daily life. They always say "I want", "I think", "I accept", "I refuse" and "I can't accept" - and "I" is the core phrase to enhance their self-awareness. Similarly, in western culture, human rights are emphasized. Children are expected to become financially independent earlier in their adulthood than in many Asian cultures and it is generally less common for parents' to interfere in their children's interests or choice of occupation. In social life, people seldom consider the factors of age and status, yet pay attention to the equality between individuals and respect personal privacy.

In Chinese culture, since ancient times, people have experienced many changes of dynasties in the Central Plains. After the unification of the country, the emperor adopted many spiritual and moral standards to govern the country, such as the feudal moral behavior principle - Three cardinal guides [i.e. ruler guides subject, father guides son, and husband guides wife] and five constant virtues [i.e. benevolence(仁), righteousness(义), propriety(礼), wisdom(智) and fidelity(信)] as specified in the Confucian ethical code.

Since ancient times, people have emphasized obedience. In order to avoid differences and conflicts, 
they always consider the needs of others and think and act from the perspective of others. The main characteristics of collectivism in Chinese culture are "we" consciousness and group orientation.

When people make some achievements, they often give the credit to their small group or even the country. In sports competitions or TV and film competitions in which Chinese people participate, it is common for competitors to mention the state or the collective when he or she wins a medal, which means that collectivism is deeply rooted in people's lives and is highly valued.

In the worldwide outbreak of new corona virus in 2020, the Chinese people have reflected the concept of high collectivism. In order to contain the epidemic, the whole country has restricted living quarters, traffic, businesses, shops and tourism. Although there are huge economic pressures, each individual is highly subject to the management of the community and the country.

This cultural psychological difference is reflected in the language of daily life, especially in the use of polite expressions. Due to the different cultural backgrounds between English speakers and Chinese speakers, there are differences in the expressions of English and Chinese polite expressions.

China's cultural background leads to the formation of the same politeness principle in the whole society, such as respecting elders and loving the young, inferiority of oneself but respect for others. For western countries, this cultural concept of "superior and inferior" is unfair and unacceptable. The western culture originated from ancient Greece, so the Western emphasis on the legal system rather than interpersonal relationship, they highlight the role of individuals in society, so individualism prevailed. English and Chinese cultural backgrounds influence two different cultural concepts, thus forming two different kinds of politeness expressions (Ning Fangfang, 2020). In the use of some words, with the development of science and technology and society, some new things will appear but disappear with the passage of time. For example, China's "大锅饭 big pot meal" was a special collective dining style in the 1960s; the “红卫兵 Red Guards" were a group of young people who blindly supported Chairman Mao Zedong in the cultural revolution;

Lei Feng was a hero in Mao Zedong times, he was expected to serve others selflessly, and his name Lei Feng was named as a typical hero in the following times.

All these words are the label of that time and are influenced by the political policies of that time. After many years, these words almost disappeared, unless deliberately mentioned. If Chinese students and foreigners mention these words, foreigners will certainly not understand. Another example is "long time no see." In Chinese "好久不见 no see for a long time" is a word to word translation model in which pragmatic transfer fails. As time goes on, Westerners finally accept this greeting expression. Language is dynamic, and this feature should also be considered in cross-cultural communication.

\subsection{The Differences in Patterns of Thoughts}

In thousands of years of human culture, the eastern countries represented by China have been in a relatively stable historical environment. People have the same cosmology, political system, moral standards, ethical norms and even living habits. But the West has experienced many shifts in its central status, and the democracy was people's rule. In modern times, the West has led the development of various fields to a higher level in the world. What are the reasons for the different development rates between the East and the West? In addition to the differences in economic power, people's patterns of thoughts between the East and the West are also a major cause of the difference.

Patterns of thoughts are common, but also individual. Ethnic groups with different cultural backgrounds may tend to use different ways of thinking when dealing with the same problem, and gradually form different thinking modes, which highlight the differences in the forms of language expression, thus forming obstacles for communication between different ethnic groups (Guan Zhenbin, 2007)[11]. Western thinking is analytical, individual, objective and systematic; Eastern thinking is 
comprehensive, holistic, subjective and non-systematic (Guan Zhenbin, 2007)[11]. In Englishspeaking countries, the speaker or writer tends to organize his/her standpoints and expresses them explicitly and directly. The listeners or readers can receive these messages with little inference. But Chinese people endeavor to avoid conflicts and take a mean course while they are thinking. In China, the speaker or writer is inclined to organize his/her standpoints and express them implicitly and indirectly. The listeners or readers receive the messages by inferring or surmising the implication.

Westerners pay attention to abstract thinking, while Chinese pay attention to imaginal thinking; westerners prefer contrast thinking, while Chinese prefer uniform thinking; westerners are accustomed to analytical thinking, while Chinese are accustomed to synectic thinking; westerners like formal logic thinking, while Chinese like dialectical thinking; westerners like linear thinking, while Chinese like non-linear thinking. When we cannot understand non-linguistic behaviors, a misunderstanding occurs due to a lack of non-linguistic awareness.

Chinese people respect Confucianism and pursue the idea of "the golden mean." They seek to be cautious and careful in their behaviors and sincere in dealing with problems. In contrast, westerners consider ambition as a manifestation of ability. Children accept the values of self-reliance and selfimprovement from childhood; people are very bold and ambitious in behavior (Ning Fangfang, 2020)[12].

If we fail to appreciate differences in the patterns of thoughts, we will not be able to understand some language behaviors and easily experience failure in communication.

\subsection{Lack of Pragmatic Knowledge}

Since the 1950s and 1960s, western scholars have put forward many systematic theories in pragmatics, such as Grice's cooperative principle, Leech's politeness principle, Brown and Levinson's face threaten theory. Although these theories cannot fully explain and guide the communication behavior of Chinese culture, we can learn from them and think about how to use them in combination with the real situation in China. Therefore, since the 1980s and 1990s, many Chinese scholars have summarized many pragmatic theories with Chinese characteristics. In his article "Politeness, pragmatics and culture" published in 1992, Gu Yueguo[13] creatively put forward five politeness principles:

(i) The self-denigration maxim: The maxim consists of two clauses or sub-maxims: (a)

denigrate self and (b) elevate the other.

(ii) The address term maxim: The maxim reads: address your interlocutor with an appropriate address term. it involves (a) speaker's recognition of hearer as a social being in his special social status or role and (b) speaker's definition of his social relation with hearer.

(iii) The refinement maxim: The maxim refers to self's behavior toward the other which meets certain standards.

(iv) The agreement maxim: The maxim refers to efforts made by both interlocutors to maximize agreement and harmony while minimizing disagreement between them.

(v) The virtues-words-deeds maxim: The maxim refers to minimizing cost and maximizing benefit to the other at the motivational level, and maximizing benefit received and minimizing cost to self at the conversational level.

Through pragmatic investigation, Bi Jiwan(1996)[14] points out that Chinese cultural politeness has four characteristics: respect and modesty, mutual concern, mutual understanding and sincerity. Previous studies have laid a foundation for the generalization and research of politeness in Chinese culture. (Wang Duan, 2020)[15].

Mey(2001)[16] summed up the causes of pragmatic failure according to deficiencies in the following five aspects: communicative competence, grammatical competence, textual competence, 
sociolinguistic competence and conversational strategy competence. The first two kinds of deficiencies are reading and writing ability in the language aspect, while the latter three kinds of deficiencies instruct us to focus on the cultivation and improvement of language application ability. There are many reasons for pragmatic failure. In order to avoid these situations, we should start from these five aspects at the same time (Zhang Jibo, 2019)[10].

\section{Implications for Foreign Language Teaching}

With the development of transportation and communication technology, the communication between the East and the West is getting closer and closer. The concept of equality in cross-cultural communication is also recognized by more and more people. Not only Chinese learners of English, but also western learners of Chinese should make efforts before and after the communication. Therefore, based on the above analysis of the causes of pragmatic failure, in the future of foreign language teaching, both English teachers and TCFL teachers should start from the following aspects.

Besides ensuring the correct expression of words and grammar, they should also consider the appropriateness of the language to help students improve their pragmatic competence. Different contexts have different language expressions. Only by standardizing the use of language and understanding expression habits can we achieve resonance in communication, thus avoiding the consequences of communication failure in the cross-cultural language environment.

Based on the reasons in the second section of this paper, this chapter adopts the method of induction, which has certain insights into foreign language teaching.

\subsection{Pay Attention to the Cultivation of Cultural Awareness}

In the process of language teaching, the basic principle that must be followed is to integrate the teaching of cultural background knowledge. Cultural awareness affects the effect of language learning and use. It plays an important role in the success of cross-cultural communication. We should take the establishment and enhancement of students' cross-cultural awareness as one of the key points of second language teaching.

Both teachers who teach Chinese students English and Chinese teachers who teach western students Chinese should conduct students to respect and tolerate different cultures, recognize the differences between different cultures, understand each other's customs and habits, understand the identity, status, religious beliefs and other sensitive issues of the communication object in advance, and accept the etiquette and code of conduct of "When in Rome, do as the Romans do."

In order to get effective teaching results, teachers, students, and the school should get unit to achieve the results.

Teachers should provide corresponding cultural information when teaching texts, so that students can master the cultural background knowledge embodied in the text, and effectively improve classroom teaching. In addition, teachers should choose authentic teaching materials. Authentic teaching materials refer to materials selected from real communication context, because the quality of teaching materials determines the effect of classroom teaching to a certain extent. When choosing authentic foreign language materials, the selection of dialogue part is very important, because the dialogue more truly reflects the relationship between communicators, and the instructor explains purposefully cultural background makes communication more authentic.

Students should realize that the cultivation of cultural awareness is not overnight. Under the guidance of teachers, students must gradually cultivate their cultural awareness and sensitivity to culture through extensive reading, including original novels, magazines and English newspapers. For most learners, reading literary works is the quickest and most effective strategy to cultivate their 
cultural awareness, because literary works reflect the psychology, cultural character, customs and social relations of people. Reading these cultures will only be accepted implicitly. In addition, learners must seize the opportunity to speak target language in the learning process, especially when chatting with native people. The more relaxed the environment is, the more easily they can acquire more cultural knowledge, which can never be learned in class.

The school should make efforts to create conditions for students to feel the necessity and importance of cross-cultural learning, such as organizing more exchange opportunities and interaction opportunities between Chinese and non-Chinese students. Allowing students to participate in shortterm language training programs or work as teaching assistants in these kinds of activities are also good methods.

Such experience would help the students to enhance cross-cultural sensitivity and identity. Due to the differences in the implementation of language behavior rules, to be familiar with the behavior rules of each language and improve the proficiency of the language is an undertaking of great significance.

Language and culture are inseparable. Language and culture are interdependent. Learning a language is also learning a culture. After realizing this, teachers should accumulate more useful cultural knowledge, because the mastery of cultural knowledge can reflect the learning situation of language to a certain extent. Moreover, each culture has its characteristics, which cannot be replaced by other cultures. In a word, the more deeply and carefully the learners master the cultural knowledge, the more fluent their communication is.

Teachers should create a real language environment in the teaching process of reading, audio-visual and communication through classroom or extracurricular activities, cultivate students' consciousness of thinking and communicating in the target language, and provide students with more opportunities to read works in the original target language, which can provide authentic language norms for learners.

In addition to the original works, in recent years, due to more developed network technology, "We"media practitioners have also increased unprecedentedly. The era of we-media has emerged. In order to gain people's attention, these we-media participants will try to explore vocabulary differences or natural language expression, and provide learners with more perspectives on language learning through fragmentary, unsystematic but practical language fragments.

Tiktok also has many non-free APP on advertisement. The owner of the APP stimulates the learning desire of learners through advertisements in diverse methods. They provide some methods such as etymology in memorizing words, the contrast between Chinese and English in traditional expressions, or effect display method. If the students have a lot of contacts with cultural products of the target language and foreign social media, they can use the target language more idiomatically and regularly, so that they can avoid pragmatic failure.

After discussing the cultural differences and thinking patterns in the second section of this paper, we should pay attention to the cultivation of cultural awareness in third section. In view of the deficiency of pragmatic knowledge explored in the second section, we point out that we should pay equal attention to the input and output of pragmatic knowledge. In third section, we also put forward a way of creating real context.

With the popularity of the $5 \mathrm{G}$ technology, various real contexts are becoming more and more convenient, English and Chinese learners face more and more opportunities for real communication. We hope this paper can play a certain role in helping the 200 million English and Chinese learners avoid pragmatic failure.

\subsection{Input and Output of Pragmatic Knowledge}

In the input process of pragmatic knowledge, teachers should pay attention to the cultivation of teachers' pragmatic awareness first, which cannot be ignored. Yang Huijuan(2019)[17] analyzes the 
causes of teachers' pragmatic failure from the internal aspects such as pragmatic awareness, cultural literacy, pragmatic knowledge, register selection ability, and external aspects such as English textbooks and tests, teacher training and so on. Some suggestions are put forward, such as the cultivation of pragmatic awareness and cultural literacy, the reform of teaching materials and testing, and the development of overseas study programs. It also provides a new perspective for pragmatic input.

The proportion of Chinese students' pragmatic failure is relatively high, because the traditional English teaching methods only pay attention to vocabulary and grammar learning, so students naturally think that English learning is to learn language knowledge, but they do not pay attention to the cultivation of pragmatic ability. In view of this, learning pragmatic principles is one of the effective means to reduce pragmatic failure.

Pragmatic strategies are various ways for language users to achieve their communicative purposes. Any language has pragmatic strategies, and each language may have multiple strategies to perform a language act. In different teaching stages, teachers should teach students different language behavior strategies and expand them gradually.

At the same time, teachers should emphasize the importance and necessity of the diversity of pragmatic behavior strategies as much as possible, so that students can consciously adopt multiple language behavior strategies in order to correctly and skillfully communicate with each other.

Some studies have shown that even though learners might already know the relevant pragmatic knowledge, there are still pragmatic failures in actual communication. Pragmatic productive competence is inconsistent with pragmatic knowledge competence, which is rooted in the fact that learners fail to translate pragmatic knowledge into behavior (Lu Jiawei, 2010)[18].

In cognitive analysis and process control, learners' pragmatic awareness cannot regulate the attention to appropriate speech acts at any time. In the process of second language acquisition, it is necessary to consciously learn declarative knowledge, that is, to learn and memorize meta pragmatic knowledge. Then, through extensive practice, learners can gradually transform part of the declarative knowledge into procedural knowledge, so as to improve accuracy and fluency.

Finally, again after extensive practice, the use of the language automatically becomes fast and accurate in different contexts (GuJie, Lu Renshun, 2016)[19]. Therefore, in addition to the input of pragmatic knowledge, the use and output of pragmatic knowledge is also a very important aspect.

As mentioned above, the input of pragmatic knowledge helps to reduce pragmatic failure. Can pragmatic knowledge teaching improve learners' pragmatic competence? This paper set up a pragmatic teaching experiment to verify it.

\subsection{Experimental Design}

\subsubsection{Experimental Participants}

This paper selected 40 high-level Chinese learners as subjects, including 20 students in one class as the control group and 20 students in the experimental group in the other class. There were 29 girls and 11 boys. The average age was 17 years old. All the students are from Chungcheongnamdo, South Korea. With more than two years of the professional Chinese learning experience, the students' Chinese level is almost the same.

\subsubsection{Experimental Process}

The experimental group received 8 hours of pragmatic courses, while the control group did not. The teaching content is from the previous pragmatic knowledge, introducing the politeness principle and face theory to students, and introducing politeness terms by category (Wang Shuai, 2016)[20]. The 
process is: Watch video and introduce pragmatic theories ---practical practices --- teacher's correction and summary.

\subsubsection{Experimental Result}

Before the test, the average scores of the two groups were 70 and 69 respectively, and after the test, the average scores of the two groups were 71 and 80 respectively. According to the results of paired sample t-test in SPSS, the p-value of the experimental group is 0.0000 , less than 0.05 , which indicates that the performance of the experimental group has been significantly improved, and the pragmatic ability has been improved. While the control group SPSS paired sample t-test results showed that P value was 0.288 , greater than 0.05 , indicating that the control group did not improve the performance. The results of the independent sample t-test of SPSS were given to the experimental group and the control group, P-value was 0.0000 , less than 0.05 , indicating that compared with the control group, the score of the experimental group was significantly improved.

The teaching of pragmatic awareness is helpful to the improvement of students' pragmatic performance and can effectively avoid pragmatic failure.

\section{Conclusion}

In today's society with increasingly developed Internet technology and transportation, the communication between countries has prospered to an unprecedented degree. With the improvement of China's international status, there are more and more Chinese learners. Therefore, the significance of this paper is to strengthen the bilingual environment of studying Chinese and English. Students understand the causes of pragmatic failure in the learning process, and they will learn what should pay attention to and avoid pragmatic failure in the process of learning and using. Pragmatic experiments in this paper have proved the effectiveness of pragmatic teaching. There is also a great significance to the cultivation of teachers' pragmatic awareness. In the process of students' foreign language acquisition, teachers, schools and even the society, who perform as educators, should respect each other's culture as the principle of communication, both Chinese learners and English learners should be familiar with each other's culture background and thinking pattern as much as possible in addition to learning the language itself, moreover, pay attention to the cultivation of pragmatic awareness. In classroom teaching, the improvement of pragmatic competence can start from the integration of cultural knowledge teaching, context-based teaching and a lot of practice and output. At the same time, both teachers and students should pay more attention to professional theoretical knowledge to avoid pragmatic failure in daily communication. Because pragmatic failure is much more serious than language failure. The limitation of this paper is the number of the sample is small, and the corpusis insufficient. It is hoped that in future research, researchers can further explore the causes of pragmatic failure and use more scientific and modern methods to make this field more professional.

\section{References}

[1] J. Thomas, Cross-cultural pragmatic failure, Applied Linguistics, (1983), Vol.4, No.2, pp.91-112.

[2] Dan Sperber, Deirdre Wilson, Relevance: Communication and Cognition, Blackwell's, Oxford, (1986)

[3] Hong Gang, A survey of English pragmatic competence and its implications for foreign language teaching, Journal of Foreign language teaching and research, (1991), No.4, pp.56-60.

[4] Xiong Yanbing, Zou Zhiyong, Errors and correction in second language acquisition, Journal of Educational theory and practice, (2008), No.21, pp.50-51. 
[5] LvTiejin, Analysis of L2 pragmatic failure in intercultural communication and its implications for foreign language teaching, Journal of Jingdezhen University, (2016), No.2, pp.71-76.

[6] Hao Ying, Pragmatic failure analysis and strategies in Intercultural Communication, Heilongjiang University, Master's Thesis, (2018)

[7] Chen Yating, Interpretation of adaptation theory in interlanguage pragmatic failure and intralingual pragmatic failure , Fujian foreign language society, (2008), pp.827-833

[8] Dai Yuanfang, A study on the relationship between pragmatic competence and pragmatic transfer of Chinese EFL learners under the bilingual theory, Northeast Normal University, Doctoral Dissertation, (2020)

[9] Zhang Jibo, Analysis of the influence of cross-cultural pragmatic failure on College English Teaching, Journal of Intelligence, (2019), No.33, pp.136-137.

[10] Shao-xia Liu, Mun-Koo Kang, The Description of Chinese Students' Pragmatic Transfer Failure, Asia-pacific Journal of Multimedia Services Convergent with Art, Humanities, and Sociology, (2019), Vol.9, No.6, pp.303-312.

[11] Guan Zhenbin, Analysis of pragmatic failure in Intercultural Communication, Journal of Huangshi Institute of Technology (HUMANITIES AND SOCIAL SCIENCES), (2007), No. 1, pp.97-99, p.115.

[12] Ning Fangfang, Pragmatic failure of English and Chinese Polite expressions, Journal of Modern communication, (2020), No. 5, pp.64-65.

[13] Gu Yueguo, Politeness, pragmatics and culture, Journal of Foreign language teaching and research, (1992), No.4, pp.10-17, p.80.

[14] Bi Jiwan, A study on the cultural characteristics of politeness, Journal of World Chinese teaching, (1996), No.1, pp.52-60.

[15] Wang Duan, On the cultivation of pragmatic competence in foreign students' Chinese classroom from the perspective of pragmatic failure of polite expressions, Journal of Jilin University of education, (2020), Vol.36, No.4, pp.95-98.

[16] J. L. Mey, Pragmatics: An introduction, Beijing: Foreign Language Teaching and Research Press, (2001), pp.76-80.

[17] Yang Huijuan, A study on pragmatic failure of junior middle school English teachers from the perspective of Intercultural Communication, Hangzhou Normal University, Master's Thesis, (2019)

[18] Lu Jiawei, A review of studies on the influencing factors of pragmatic transfer, Journal of Ocean University of China: Social Science Edition, (2010), No. 2, pp.101-105.

[19] Gu Jie, Lu Renshun, Pragmatic transfer and its implications for foreign language teaching, Journal of East China University of Technology (SOCIAL SCIENCE EDITION), (2016), Vol.35, No.02, pp.142-146.

[20] Wang Shuai, Exploration of Chinese Pragmatic Teaching - Taking "request" as an example, Language application, (2016), No.1, pp.94-103, doi:10.16499/j.cnki.1003-5397.2016.01.013. 